\title{
Decentralization: An Incomplete Ambition
}

\author{
Nathan Schneider \\ University of Colorado Boulder \\ PREPRINT \\ Journal of Cultural Economy (2019) \\ https://doi.org/10.1080/17530350.2019.1589553
}

Decentralization is a term widely used in a variety of contexts, particularly in political science and discourses surrounding the Internet. It is popular today among advocates of blockchain technology. While frequently employed as if it were a technical term, decentralization more reliably appears to operate as a rhetorical strategy that directs attention toward some aspects of a proposed social order and away from others. It is called for far more than it is theorized or consistently defined. This non-specificity has served to draw diverse participants into common political and technological projects. Yet even the most apparently decentralized systems have shown the capacity to produce economically and structurally centralized outcomes. The rhetoric of decentralization thus obscures other aspects of the re-ordering it claims to describe. It steers attention from where concentrations of power are operating, deferring worthwhile debate about how such power should operate. For decentralization to be a reliable concept in formulating future social arrangements and related technologies, it should come with high standards of specificity. It also cannot substitute for anticipating centralization with appropriate mechanisms of accountability.

This article has benefited from substantive feedback by Ugo Biggeri, Andrew Calabrese, Gabriella Coleman, Bob Haugen, Travis Higgins, Brent Hueth, Carla Ilten, Janne M. Korhonen, Vince Kuraitis, Rhys Lindmark, Morshed Mannan, Taylor Nelms, Sam Pospischil, Adrienne Russell, and Philip Sheldrake, as well as anonymous reviewers. 


\section{Introductory rituals}

There is a common practice, in examinations of decentralization such as this, to begin by expressing dismay at the want of rigor surrounding usage of the term. I will argue that this lapse is no accident, and that it serves specific purposes. But we can still bow to common practice. In lieu of rehearsing the particular frustrations that motivated this investigation, a selection of previously published complaints should suffice.

- "A quick review of the literature shows that there is no common definition or understanding of decentralization, although much work has gone into exploring its differing applications" (UNDP \& Government of Germany, 1999, p. 1)

- "Scholarship is littered with so many different usages of these words that is often unclear just what they mean, if indeed they still mean anything at all" (Treisman, 2002, p. 2) ${ }^{1}$

- "Despite increased research, there remains a great deal of conceptual confusion. Researchers attach a startling diversity of definitions and measures to the decentralization concept" (Schneider, 2003, p. 32)

- "'Decentralization' is one of the words that is used in the cryptoeconomics space the most frequently, and is often even viewed as a blockchain's entire raison d'être, but it is also one of the words that is perhaps defined the most poorly" (Buterin, 2017)

- "It seems like [many of the Bitcoin folks] are trapped in some horrible Sartre play where everyone has to use the word 'decentralized' to mean different things" (Green, 2017)

The collective exasperation may be overstated, since most of those complaints precede sensible attempts to address it. In political science especially, and to some degree in fields such as computer science, critical theory, and economics, there is already a considerable and compelling literature that hones decentralization into a meaningful term or family of concepts. Yet causes for such definitional concerns persist.

Lately, the promise to decentralize $x$ - or everything - is as ubiquitous in the heady realm of blockchain-based technology as the promise to "disrupt" has been among those seeking venture-capital investment in Silicon Valley. Just as allegedly disruptive startups don't necessarily conform to scholars'

\footnotetext{
${ }^{1}$ The article also begins with this epigraph from Alexis de Tocqueville (2004): " 'Centralization' is now a word constantly repeated but is one that, generally speaking, no one tries to define accurately."
} 
definitions of disruption, this decentralizing enthusiasm has rarely heeded the most cogent methodological proposals. It is an ambition that holds welldeserved appeal, but like any ambition its appeal deserves commensurate scrutiny.

Tensions between people's understandings of decentralization and real-world outcomes have escalated into an identity crisis for some leading technologists. For instance, Internet Archive founder Brewster Kahle has hosted Decentralized Web conferences in 2016 and 2018, seeking to counter the Internet's perceived centralizing trajectory, in collaboration with TCP/IP co-inventor Vint Cerf and World Wide Web inventor Tim Berners-Lee. Tech activists in London held a similar Redecentralize Conference in 2015. Berners-Lee co-directs a Decentralized Information Group at the Massachusetts Institute of Technology. These projects' motivating frustration goes something like this: The underlying protocols for the Internet and the Web work owe their benefits and health to their decentralized architectures, yet they have become infected with centralized pathogens, such as government censorship and monopolistic corporations predicated on user surveillance (Benkler, 2016; Brooker, 2018; Kahle, 2015). The proposed cures are chiefly technical ones, such as new distributed networks and blockchain protocols.

In the discourses surrounding blockchain-based crypto-networks, decentralization has come to assume a heightened heft and significance; rather than regarding it merely as a technical characteristic, they treat decentralization as a way of life. They have synthesized decades and even centuries of arguments for decentralized systems, from Adam Smith to Satoshi Nakamoto, into a guiding ideology.

Scholars of media and technology have long noticed the contradictions at work in the rhetoric of decentralization. Winner (1986) found that the claims about decentralization in early computer culture paled in comparison to the centralized institutions surrounding them. With the Internet age well underway, Galloway (2006) further analyzed its alleged decentralization as a new form of totalizing management through the specification of protocolsindeed, "the most highly controlled mass media hitherto known" (p. 147). ${ }^{2}$ Golumbia (2016) more recently pointed out that, thanks to the guise of decentralization, regulators have allowed online media to centralize to an extent that previous broadcast regimes never could. As calls for decentralization grow only louder, we are due for a better understanding of what purposes this brood of contradiction is serving.

\footnotetext{
${ }^{2}$ Emphasis in the original, here and elsewhere.
} 


\section{Argument and structure}

The method of what follows is a survey of scholarly and popular usage surrounding decentralization - identifying common themes, anxieties, and oversights. While frequently employed as if it were a technical term, decentralization more reliably appears to operate as a rhetorical strategy that directs attention toward some aspects of a proposed social order and away from others. It is called for far more than it is theorized or consistently defined. This non-specificity has served to draw diverse participants into common political and technological projects. Yet discourses of decentralization tend to take on a tragic hue, and justly so; even the most apparently decentralized systems have shown the capacity to produce economically and structurally centralized outcomes. The rhetoric of decentralization thus obscures other aspects of the re-ordering it claims to describe. It steers attention from where concentrations of power are operating, deferring worthwhile debate about how such power should operate. For decentralization to be a reliable concept in formulating future social arrangements and related technologies, it should come with high standards of specificity. It also cannot substitute for anticipating centralization with appropriate mechanisms of accountability.

More than offering a unified theory of decentralization (or centralization) as such, I am proposing an analysis of its uses. The uses explain more than the term itself usually does.

In thinking of decentralization as a mode of directing attention, I draw on notions of attention as an economy (Goldhaber, 1997) and theories of selective communication through framing (Entman, 1993). Further, I suggest that decentralization serves as a floating signifier (Mehlman, 1972) that broadcasts fluency and belonging in discourse communities that must remain less than fully specified in order to make their liberatory promises (Jones \& Spicer, 2005). The lack of clarity around the term is functional, in that it enables people of varying ideological persuasions to imagine themselves as part of a common project. As a feat of performativity (Schechner, 2017), this political and technological strategy has proven useful-delivering structural change for governments around the world and inventions no less significant than the Internet. Critique does not constitute dismissal. Such signifiers need space to float. Yet a signifier cannot float forever.

This study puts into conversation three main interlocking discourses of decentralization: political theory, early computer networking, and cultures surrounding blockchain-based crypto-networks. Frequently these discourses 
operate in parallel, mostly independently and without reference to each other; in such cases, the isomorphic similarity among them is telling. But invariably these discourses also intersect, particularly when participants use other domains to reinforce the appeal of their own. Reference to the politics presents a technological project as a more holistic social movement; reference to technological jargon lends political claims the veneer of scientific legitimacy. Although the meanings of decentralization differ across discourses, this study shows that its uses - and misuses - are roughly consistent.

First, I review varieties of allure that decentralization has held, including in economics, politics, military strategy, and social movements, together with discourses of networked media. As these lineages interact and combine, the term migrates from being a means for certain ends to nearly an end in itself, thanks to the performative functions it has come to hold in certain subcultures.

Second, particularly in the contexts of political science and computer networks, I present common definitions and distinctions surrounding decentralization, revealing highly (and conveniently) heterogeneous usage. Part of the term's power derives from its multiplicity, which has enabled it to operate not just as technical vocabulary but as a political project.

Third, the evidence of literature across several fields suggests that processes of decentralization in one part of a system seem to enable centralization in another. It appears, therefore, that decentralization typically does not fully characterize the changes it purports to describe. The allure of decentralization-talk may obscure these effects, even to the point of undermining the decentralizing ambitions altogether.

Finally, I propose avenues for more responsible uses of decentralization. When we recognize that decentralizing one part of a system can have centralizing effects in other parts, we can better prepare to notice and accommodate those effects. Doing so might prevent such centralization from undermining a decentralized design, or reveal a design to be less decentralized than advocates have claimed. I will suggest some means by which those seeking to decentralize can be prepared to design for accountable centralization as well.

\section{Ambitions}

The earliest reference to decentralization cited in the Oxford English Dictionary dates to 1846, in Popular Fallacies Regarding General Interests, 
translated from a treatise by the French laissez-faire economist Frédéric Bastiat. Countering an argument for anti-monopoly interventions, the passage goes, "If it were possible that industry could be concentrated on one point, there would rise within itself, and by its own movement, an irresistible power of decentralization" (Bastiat, 1849, p. 59). The word, borrowed from the French original, ${ }^{3}$ seemed strange enough to merit emphasis. Yet it was already "irresistible."

The word's "power" lies in its allusion to a kind of invisible hand, that founding mythology of liberal economics which grants markets a life of their own; if left alone, that is, market outcomes will accord with the general welfare. Bastiat promises an affable entropy, a natural demise sure to come for over-concentrated firms if only authorities step back and relinquish centralized control. That such a thing could be possible was a defining epiphany of early modernity, which would find expression in Darwinian biology as well as Smithian economics, then eventually in the craft of computation. The analogies in favor of decentralized processes became easy to find: nature generates order not by primordial design but through natural selection among organisms; wealth flows toward open, diverse markets more eagerly than it follows autocratic commands. What other human errors might be remediated with decentralized forces?

\section{Political cultures}

Decentralizing themes have characterized diverse currents in political thought. Alexis de Tocqueville muses on centralization and its opposite throughout his reflections on America and the French Revolution (Tocqueville, 2004; Tocqueville, Furet, \& Mélonio, 1998). Fontana (2018) identifies decentralization as a basic feature of US constitutional law. Business-oriented conservative factions have frequently claimed the liberal, anti-interventionist view that figures like Bastiat and Friedrich Hayek championed, while popular movements and avowed progressives have had decentralizing impulses of their own. Far-leftist libertarians have sought their own sort of decentralization, under the analogous label of anarchism (Winner, 1986), as have popular movements of various pedigrees seeking to challenge concentrations of power. For instance, the late-nineteenth-century US Populists called for multi-metallic currency, as opposed to a gold standard, and for antitrust policies meant to shatter overly centralized markets, keeping vigorous the fray of competition

\footnotetext{
${ }^{3}$ Which reads, with no emphasis, "une force irrésistible de décentralisation."
} 
(Goodwyn, 1978). These impulses have found new life recently, whether among people instigating alternative currencies or the "hipster antitrust" bloc (Meyer, 2018) seeking to confront the market power of dominant online platforms.

Religious communities have felt a parallel allure, most obviously for Christianity in the decentralizing impulses of the Reformation and anti-hierarchical Congregational model that enabled so much New World experimentation (Finke \& Stark, 2005). Yet no less central an authority than Pope Leo XIII (1891) proposed to resolve conflicts of labor and capital through economic policies that "induce as many as possible of the people to become owners," distributing the means of production among those involved in their use. After him, Catholic thinkers like G. K. Chesterton and Hilaire Belloc attempted to craft a political philosophy of "distributism" on that basis (Mathews, 2009). Integral to this discourse has been the principle of subsidiarity, according to which authority should operate as locally as possible in a nested hierarchy. Pope Pius XI (1931) regarded the matter as a moral imperative, writing, while marking the fortieth anniversary of Leo XIII's exhortation, "It is an injustice and at the same time a grave evil and disturbance of right order to assign to a greater and higher association what lesser and subordinate organizations can do."

Perhaps no discourse of decentralization has been as robust or effectual as that in the practice and theory of political institutions - particularly in postcolonial regions, under the shadow of "structural adjustment" pressures from the World Bank and the International Monetary Fund. In the latter decades of the twentieth century, decentralization became a byword for a variety of reforms meant to disentangle centralized colonial systems, which frequently became untenable planned economies after independence (Olowu, 2001). The urge to decentralize has offered the promise of bypassing central governments regarded as corrupt, facilitating private enterprise and foreign investment, and fostering more responsive political and civic institutions through local accountability (Bonnal, n.d.). The concept has had powerful advocates, but it also finds plentiful critics, who found voice especially through the movement alternately referred to as seeking "anti-globalization" or "global justice."

Resistance movements have adopted decentralization discourses of their own. In struggles for independence from colonizers, Frantz Fanon (2007) called for bottom-up organizing and popular education in these terms: "We ... must decentralize to the utmost" (p. 138). Afterward, activists seeking 


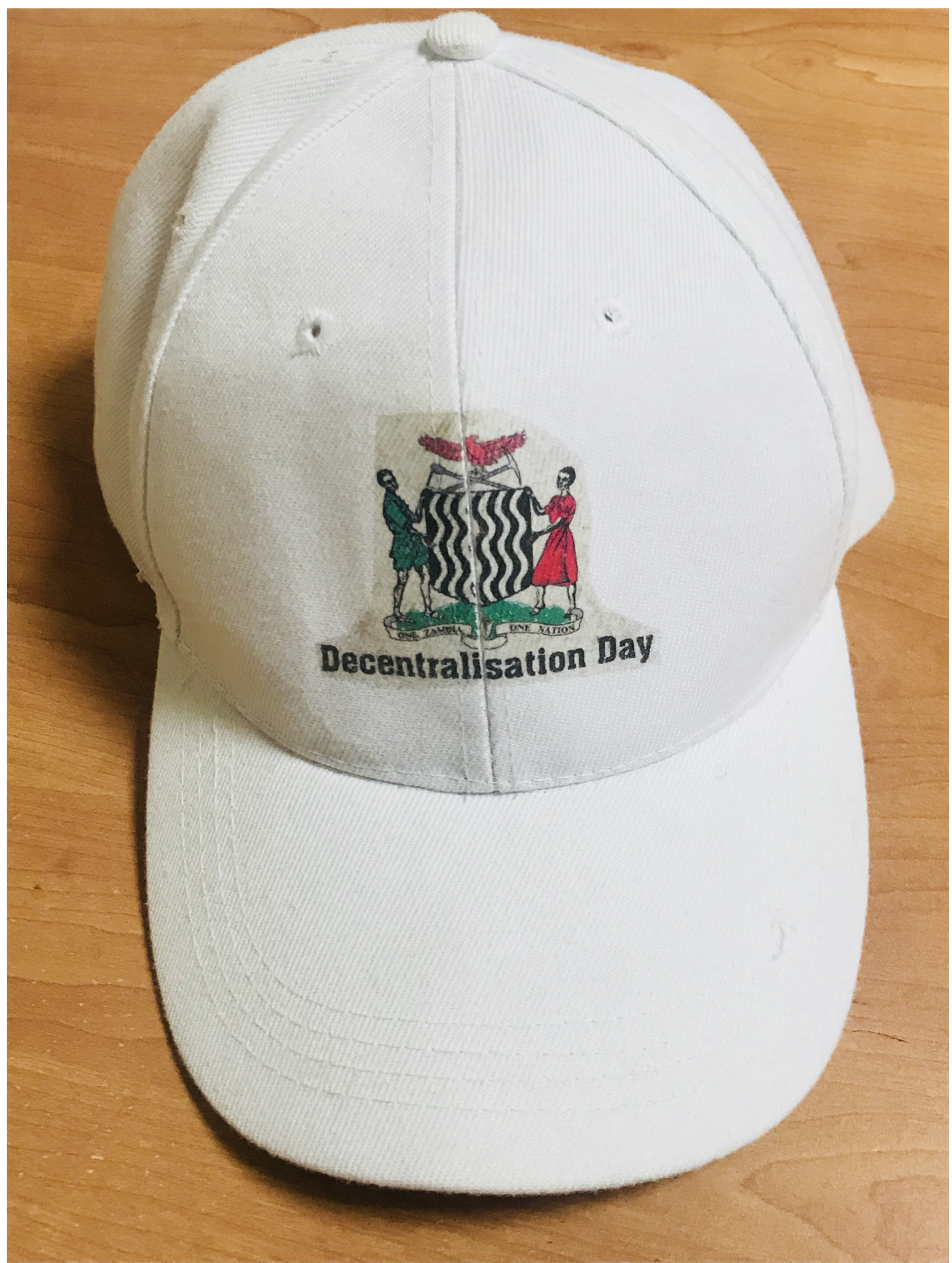

Figure 1: Hat from a 2013 event sponsored by Zambia's central government celebrating a decentralization process. Courtesy of Elizabeth Sperber, a political scientist at the University of Denver. 
alternatives to the corporate and political order adopted the metaphor of the "rhizome" (e.g., Deleuze \& Guattari, 1987), a structure of interconnected, heterogeneous, subterranean organisms as opposed to the roots-to-branches hierarchy of a tree. Hardt \& Negri (2005) evoked a decentralized "multitude" to explain the kind of resistance that arose against the global order through roving protests, summit shut-downs, and local insurgencies. In a report for the RAND Corporation, a US military think tank, Arquilla \& Ronfeldt (2000) refer to this kind of nonviolent resistance as "swarming," and liken it to the tactics of more weaponized resistance groups such as Al Qaeda. Their recommendations became part of a widespread effort to reform large national militaries into the networked image of their insurgent opponents (Bosquet, 2011; Ferguson, 2018). Perhaps it is no surprise, then, that in the fight against Islamic State fighters, the US military found its most effective allies among the militias of Rojava - the "democratic confederalist" Kurdish society formed in the ruins of war, whose novel political system has been frequently referred to as decentralized (e.g., Sheppard, 2016), and which attracted Bitcoin enthusiasts from abroad as recruits (Greenberg, 2017). Historian Gyanendra Pandey (2015), meanwhile, calls for celebrating the already "off-centered" nature of all nation-states - since governments' claims to unity, totality, and centralization always exceed the reality of their control.

\section{Network cultures}

By the turn of the millennium, the metaphor of a decentralized network had an obvious and ubiquitous referent: the Internet. Seeking to build a resource-sharing tool among Pentagon-funded researchers, the Internet's progenitors followed the "distributed" design that had been proposed by RAND's Paul Baran (1964); he envisioned multiply redundant communications systems without central points of failure that could remain resilient under nuclear attack (Hafner \& Lyon, 1996). The early Internet protocols were decentralized by design and necessity. Email addresses came to include both a user's handle and the host machine, which followed the "@" sign, since users had their accounts through the mainframe computers at their various institutions. World Wide Web creator Tim Berners-Lee (1999) saw decentralization as a "fundamental property" of his invention. "It had to be completely decentralized," he later wrote. "That would be the only way a new person somewhere could start to use it without asking for access from anyone else. And that would be the only way the system could scale" (p. 16). He concluded his memoir on the subject by relating this design to the radical 
openness of his Unitarian Universalist church.

Even as organizations like America Online (through Internet access), Microsoft (through its operating system), and the Recording Industry Association of America (through digital rights management) sought to organize centralized points of entry, new decentralizing protocols arose. A celebrated case was the rise of peer-to-peer file-sharing, popular especially for circulating "pirated" music files, through protocols such as Napster, Gnutella, and BitTorrent. The prospect of accessing free music, according to one observer, quickly promulgated the "democratic vision" of peer-to-peer decentralization as well as the danger of "the "moral' transgressions that it so easily allowed" (Loban, 2004). The protocols' techniques developed in a cat-and-mouse game with entertainment-industry legal action (Backus, 2018).

The thrall of decentralized networks took hold meanwhile in business. Bestselling futurist John Naisbitt (1984) counted the shift "from centralization to decentralization" among ten "megatrends" for the late twentieth century. Dee Hock (2005), founder of the Visa credit-card cooperative, dubbed his early 1970s invention a "chaordic organization"; independent members - in this case, regional banks that issued Visa cards - could compete within a shared entity with shared purpose. Tech companies have since flirted with management systems like Holacracy, which claim to replace hierarchies with nested circles and top-down control with "design without a designer" (Robertson, 2015, p. 140). New technologies repeatedly offer business the promise of "cutting out the middle man" (e.g., Katz, 1988; Gellman, 1996), or disintermediation - a rallying cry that at least one activist against Internet recentralization has since extended to "counterantidisintermediation" (Kleiner, 2016). The popular writer and risk analyst Nicholas Nassim Taleb (2016) argues that the right kind of decentralized system is more resilient and "loves mistakes" (p. 21). In their provocative vision for "radical markets," Posner \& Weyl (2018) propose decentralizing reforms ranging from rolling back property rights to opening borders to disassembling high finance; they contend that removing fixed intermediaries at all levels can result in new efficiencies, which even the most powerful intermediaries cannot achieve.

\section{Blockchain cultures}

These impulses and more converge in the realm of crypto-networks and blockchains - a subset of the internet's decentralization discourse, while vying to be its apotheosis. The technology's progenitors and the cultures 
they birthed merge economic decentralization (through the reliance on game theoretic incentives), political decentralization (through permissionless access and bypassing state controls), and organizational decentralization (through open-source replication and user governance) to produce functional prototypes with a bewildering array of decentralizing possibilities. The language of decentralization has been foundational for articulations of these systems' appeal (Zhang, 2018).

In the second sentence of the inaugural email-list post announcing Bitcoin, the pseudonymous inventor Satoshi Nakamoto (2009b) explained, "It's completely decentralized with no server or central authority." Completely. A month later, Nakamoto (2009a) introduced the idea again on the P2P Foundation's online forum, again with "completely decentralized" in the second sentence, but with more polemic against the centralized financial institutions that had just caused a global crisis. "It takes advantage of the nature of information being easy to spread but hard to stifle," Nakamoto continued. "The result is a distributed system with no single point of failure."

Bitcoin's decentralizing promise chiefly targeted central banks and their "fiat" currencies. Many early adopters were those of libertarian, anarcho-capitalist persuasions who distrusted government management of the economy and sought a system of free markets all the way down (Maurer, Nelms, \& Swartz, 2013). Bitcoin placed the processes of money creation and transfer under the control of both hard-coded algorithms and competitive activity among network users. But it was also the start of much more. "Alt coins" began attempting to adapt Bitcoin's design to applications other than money. One early Bitcoin fork, which began in 2011, was called Namecoin; it set out to further decentralize the Domain Name System, a feature of the Internet's architecture that operates through a federated hierarchy under the Internet Corporation for Assigned Names and Numbers (ICANN). Others followed. Twister, developed two years later in Brazil, copied the functionality of Twitter but blended technology from Bitcoin and BitTorrent to enable microblogging without a central company to manage the network. Bitnation, founded in 2014 by Swedish entrepreneur Susanne Tarkowski Tempelhof, proposed a "voluntary nation" made up of government-like services, such as land titles and dispute resolution, etched on blockchain ledgers.

Such decentralized applications - typically styled as "dApps" or "ĐApps"became especially plausible with the development of Ethereum. According to the title of its original whitepaper, Ethereum represented "a next-generation smart contract and decentralized application platform" (Buterin, 2013). It 
expanded Bitcoin's blockchain technology into a fully programmable toolkit for developing software based on distributed computation, cryptographically secure data, and tokens that could obtain value on exchange markets. Ethereum promised to be for everything else what Bitcoin was for money.

While Ethereum was still in development, a group of Silicon Valley enthusiasts formed an offline and online community called the Decentralized Autonomous Society. ${ }^{4}$ Members demonstrated in online videos how to create simple programs such as, for instance, immortalizing a marriage contract "(with divorce clause)" on a blockchain (Dietz \& Bontje, 2014). Entrepreneur David A. Johnston (2014) coined "Johnston's Law": "Everything that can be decentralized, will be decentralized." Ethereum became operational in 2015, enabling a spree of new blockchain protocols and "initial coin offerings," each seeking to decentralize one or another feature of the Internet or finance or everyday life, careening toward a spike and then crash of cryptocurrency valuations in late 2017. All the while, enthusiasts enjoined each other to "HODL" (hold crypto-tokens despite the apparent free-fall) and "BUIDL" (build useful tools with crypto-tokens that provide social value). In April 2018, an online magazine called In the Mesh appeared, "dedicated to cataloguing the political economy driving the burgeoning decentralization movement" (In the Mesh, 2018); its early articles covered such topics as hurricanes, the World Cup, art, and gossip, all through the lens of decentralization. An Ethereum-based virtual-reality platform took as its name the collective destination: Decetraland.

A measure of this "movement" lies in the increasingly common characterization of decentralization as not just a design principle but a philosophical aspiration. One among many Ethereum-based projects, for instance, is Civil, "the decentralized marketplace for sustainable journalism" (Civil Media Company, 2018). The whitepaper outlining the project before the accompanying CVL token's release refers to a "decentralized goal" and the need to "truly achieve decentralization." According to a subsequent "Primer" on the token, a founder explained that the Civil protocol eventually "will not be overseen by a single, centralized authority or company, but by a community of civically engaged individuals and organizations from around the world" (Coolidge, 2018). In the meantime, however, the project was quite centrally orchestrated by a particular for-profit firm, the Civil Media Company, in tandem with a nonprofit Civil Foundation.

Among the Internet's early architects, and even more among recent blockchain

\footnotetext{
${ }^{4}$ Cf. facebook.com/groups/579940655425355.
} 
evangelists, decentralization has become a folk media theory, interwoven with a business-model logic, each reinforcing the other's appeal. It has spurred a kind of moral theory as well, and a kind of piety. As projects such as In the Mesh demonstrate, this can be a totalizing vision, a mode of seeing and being, applicable to any domain of life. Decentralization represents a range of perceived benefits from across economic, political, biological, and computational domains. It means transferring control over complex systems from constrained human minds and institutions to highbandwidth, self-regulating interactions. It means eliminating gatekeepers, enabling more widespread access to systems and more efficient, meritocratic incentives within them. The evangelists expect this will result in freedoms and efficiencies unavailable to bureaucracies of old.

In a science-fiction-themed promotional video for the Ethereum-based governance protocol Aragon (2018), co-founder Luis Cuende says, "Today, we are in the first time in history that we can actually try out new governance models without the need of people getting killed." Adds venture capitalist Chris Burniske, "Human activity can be governed on this international basis, without nation states, without corporations." Even the more measured analyses, such as De Filippi \& Wright (2018), conclude that blockchain-powered decentralization will have sweeping effects on law, policy, and politics. It is to be the basis of the next social contracts.

One would be hard-pressed to find another belief system that finds among its claimants popes, anarchists, economists, hackers, revolutionaries, engineers, and bankers. They have the word (or its gist) in common, even if little else. That can be enough to enable common projects, from assembling coalitions for reforming political structures to writing code for blockchains. The word bears Pentecostal allure that they each hear in their own language. Yet decentralization enthusiasts at times admit that their faith is a gnostic one - a rarefied set of convictions not likely to be adopted by the masses anytime soon. "Decentralization cannot be marketed," contends one participant in the Redecentralize Conference (Sheldrake, 2015); that is, beyond the tribe of true believers, the idea seems ill-suited for mass appeal.

\section{Definitions}

Despite its increasingly frequent use as a self-evident and totalizing concept, efforts to define decentralization have typically been limited to the particular domain at hand - whether, for instance, in the context of political systems 
or computer networks. People operating in each domain have discovered a lack of consistent usage even among themselves. This, however, has not prevented the concept from motivating collective action and bringing about collective disappointment.

Permanent indeterminacy can hold a legitimating function. It invites newcomers with a claim of openness to what contributions they might bring. It whispers the occult caveat that the true meanings of our words may be revealed sometime in the future, if we continue putting those words to use. Claude Lévi-Strass wrote of a floating signifier as having the "semantic function whose role is to allow symbolic thought to operate despite the contradiction inherent in it" (Mehlman, 1972, p. 23). Such signifiers induce in their users tolerance for uncertain meanings. And they also inculcate desire, such as Jones \& Spicer (2005) find in their analysis of "entrepreneur," a similarly vexing term, whose own experts continually complain about not having a usable definition. None is needed. Such terms constitute "an open space or 'lack' whose operative function is not to 'exist' in the usual sense but to structure phantasmic attachment" (p. 235). The indeterminacy of definitions holds out the alluring prospect of eventual resolution.

\section{Political meanings}

Scholars in the orbit of political science and development studies have produced a considerable literature on the meanings of decentralization, which they understand as a family of policy proposals. The most common typology (Fesler, 2008; Litvack \& Seddon, 2002; Schneider, 2003; Torrisi, Pike, Tomaney, \& Tselios, 2011; World Bank, n.d.; Yuliani, 2004) is tripartite:

- Administrative, distributing operational authority more widely among levels of government (e.g., national, regional, and municipal)

- Fiscal, distributing powers of taxation and other forms of revenue collection among levels of government

- Political, distributing decision-making powers among levels of government

Most discussions add a fourth type of market decentralization, referring to the privatization of certain government functions to independent organizations and firms, or reductions in government regulation of private enterprise.

Within these types, scholars have identified terms that frequently accompany decentralization such as deconcentration, delegation, and devolution; the 
terms' meanings vary somewhat, but generally they serve to distinguish different degrees of intensity in a decentralizing process, in ascending order. Deconcentration may involve modest redistribution of administrative control, for instance, while devolution can involve significant local autonomy from a national government (e.g., in Spain's Basque region) or even full national independence (e.g., the secession of South Sudan).

As those examples imply, this is far from a matter of merely technocratic concern. Calls for political decentralization energize popular movements, even spark wars, although those popular energies rarely adopt decentralization terminology as such. The whiff of autonomy, of independence, of liberation from the center - these lend themselves to vaguer sorts of language, which can capture longings from across a society. Decentralization serves as an umbrella term for its diverse and particular subsidiaries. Among those who use it, even if it is just the technocrats, the humble nobility of decentralizing allows them to justify their grand interventions as at least reducing concentrated power, thus preventing further grand interventions in the future by others.

All the while, political scientists assume that decentralization processes take place within the context of a hierarchical system. A governmental pyramid may be federated (where sovereignty resides primarily in the central authority) or confederated (where sovereignty resides primarily among constituent members), but one way or another, international politics expects a head of state. This is not the case in discourses surrounding the Internet and related network technologies. There, even when significant client-server or user-company hierarchies are at play, the underlying logic of a network is formally composed of peer-to-peer interactions. Internet networks can also be far more diverse in structure than national states; perhaps for this reason, network designers refer to decentralization in a more varied, you-know-itwhen-you-see-it fashion than political scientists do.

\section{Network meanings}

A classic typology in network history is that of Paul Baran (1964) - appearing as Figure 1 in a RAND Corporation document outlining a structure that would later be incorporated into the Internet's design (Baran, 2002). For Baran, the goal was actually not a decentralized network but a distributed one. What he called a decentralized network merely added clusters to the centralized one, well short of the maximally redundant and egalitarian distributed mesh. 


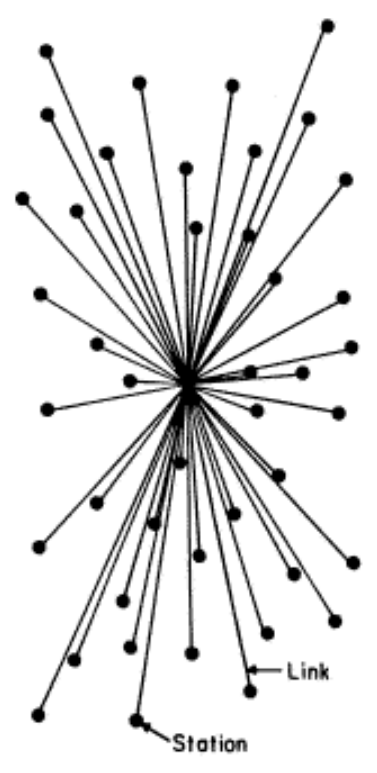

CENTRALIZED

(A)

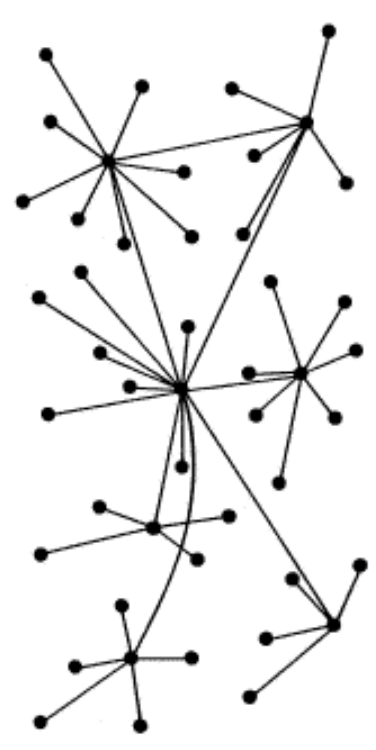

DECENTRALIZED

(B)

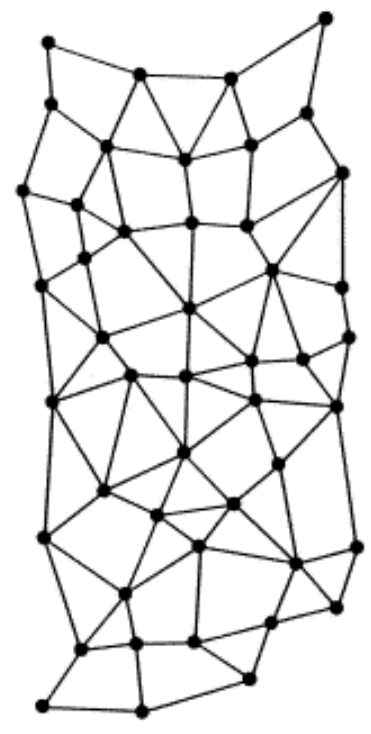

DISTRIBUTED

(C)

FIG. I - Centralized, Decentralized and Distributed Networks

Figure 2: Diagram from Baran (1964), p. 2. 
Notwithstanding this primeval articulation, the language of decentralization has been much more common in the aspirational vernacular of Internet cultures than distributedness. (The awkwardness and unfamiliarity of that noun form of the word attests to this.) Distributed computing is an important domain in computer science, dealing with techniques for coordinating computation across various sorts of networks, but it has not become a byword beyond that context. Since Baran, meanwhile, talk of decentralization has come to serve a purpose that is social at least as much as it is technical. When Tim Berners-Lee and several co-authors proposed decentralization as a strategy for online social networking, they defined it in primarily political terms - that is, what a network should enable users to do, not how it is structured. Their definition included privacy of personal data, ownership over the data, and control over the data's dissemination (Yeung, Liccardi, Lu, Seneviratne, \& Berners-Lee, 2009).

In his landmark account of "commons-based peer production," Yochai Benkler (2006) adopted a more economic formulation. Decentralization, he wrote, occurs when coordination can happen without hierarchy - when "many agents cohere and are effective despite the fact that they do not rely on reducing the number of people whose will counts to direct effective action" (p. 62). "The most pervasive mode," he added, "is the ideal market." Thus decentralization amounts to a social vision of price signals and feedback loops taking the place of willful regulation. It is by nature volatile.

In the post-Baran culture of network engineering, indeterminacy was built into the rhetoric of specification. The technical outlines of basic Internet protocols, for instance, are known in the standards-setting Internet Engineering Task Force by the name "RFCs," or "requests for comments." Although these protocols are as fixed and canonical as anything on the Internet can be, they go by a name that suggests them to be permanently up for debate, never finished, forever vulnerable to better suggestions in a global meritocracy (Galloway, 2006). Only slightly less modestly, the World Wide Web Consortium refers to its standards as "recommendations." Even where central decision-making structures exist, the imperative of decentralization demands that they belie themselves and claim to be something else.

\section{Blockchain meanings}

In a speech to a San Francisco cryptocurrency conference, the director of the Division of Corporate Finance at the US Securities and Exchange Commission 
suggested that the extent of decentralization in a system may correspond to the extent to which it no longer needs to be regulated; the system can regulate itself. "Over time," he said, "there may be other sufficiently decentralized networks and systems where regulating the tokens or coins that function on them as securities may not be required" (Hinman, 2018). Thus, what it means to "truly achieve decentralization" may have political consequences in the eyes of even the most centralized authorities. Despite the stakes, however, clear definitions remain for the most part elusive.

Vitalik Buterin first proposed the outlines of Ethereum before his twentieth birthday. In a 2017 blog post on "the meaning of decentralization," Buterin referred to the Baran diagram as "completely unhelpful" and proceeded to outline three "axes" along which centralization or decentralization might occur:

- Architectural: "How many physical computers is a system made up of?"

- Political: "How many individuals or organizations ultimately control the computers that the system is made up of?"

- Logical: relating to "interface and data structures"; "if you cut the system in half, including both providers and users, will both halves continue to fully operate as independent units?"

Blockchain protocols like Ethereum, Buterin contends, are architecturally and politically decentralized, but logically centralized, since they maintain a universal ledger based on the "consensus" of peers in the system. (A more recent cryptographic protocol, Holochain, dispenses with the single ledger in exchange for multiple, interlocking ones. And Ethereum itself demonstrated a kind of logical decentralization by forking into two parallel systems after a catastrophic hack in 2016.) For Buterin, the various forms of decentralization can make systems more resistant to breakdowns by fault, attack, or collusion. In contrast, typical online platforms that are centrally controlled by a particular company present a single, vulnerable point of failure. If Google the company is somehow compromised, so may be its entire network.

A further set of criteria and questions comes from Jamie Burke (2018), CEO of Outlier Ventures, a firm that invests in "tokenised communities that are creating the new decentralised economy." He proposes this typology, highly specific to blockchain-based networks:

- Consensus formation: "Who controls the nodes on the network and 
how is consensus achieved?"

- Protocol value: "How decentralised is the value capture in the network? How distributed is it?"

- Protocol improvements: "Who controls the product roadmap?"

- Conflict resolution: "How are conflicts resolved? How are resolutions enforced?"

- Platform development: "How many people/organisations are building on top of the network?"

Blockchain vernacular includes another set of benchmarks against which evaluations of decentralization are sometimes made. Swarming, for instance, refers to self-organizing, anti-hierarchical behavior among groups (e.g., Miller, 2015), while self-sovereignty aspires to a kind of identity management under the control of individuals themselves, rather than through the records or certifications of governments (e.g., Tobin \& Reed, 2017). Privacy advocate Sarah Jamie Lewis summarized decentralization in a tweet this way: "the degree to which an entity within the system can resist coercion and still function as part of the system" (Lewis, 2018).

Aside from a few definitional efforts in blog posts, the rapidly changing blockchain subcultures have generally deferred specifying the meaning of decentralization too much in advance. "Decentralisation could be said to be the most fundamental principle of blockchain technology," observes the Satoshi Oath, a proposed code of conduct for blockchain developers (Brekke, 2016). "But in practice, one version of decentralisation might clash with another."

The discourses of political science and Internet technology share a common fascination with the idea of decentralization, even if they apply it to quite different contexts - those of hierarchical states and peer-to-peer networks, respectively. Of course, international politics has been shaped by networks (Ferguson, 2018), and online networks have their hierarchies (Galloway, 2006). Both discourses employ decentralization as a shared byword for diverse participants and diverse rationales in complex, heterogeneous undertakings. For the sake of a common enterprise, such a term does the service of obscuring the contradictions at play - at least temporarily. 
Peer-to-peer

networking

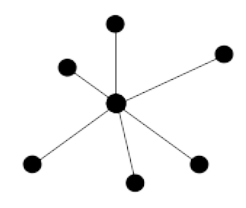

Centralized

platform
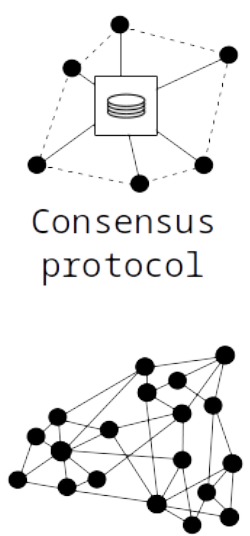

Mesh

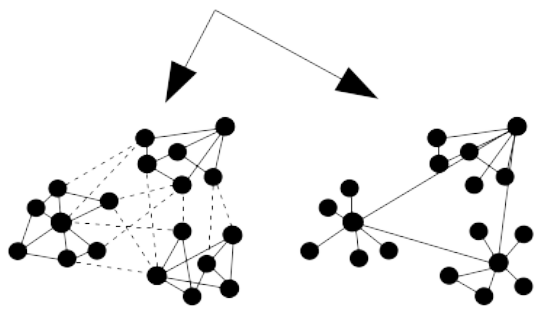

Swarming

Recentralizing

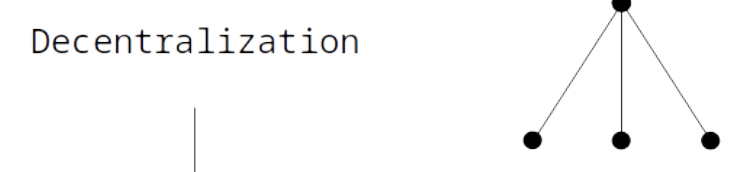

Concentrated

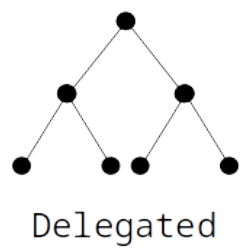

Weak

ties

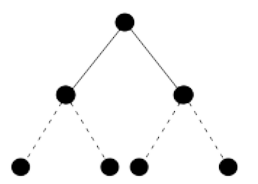

Devolved

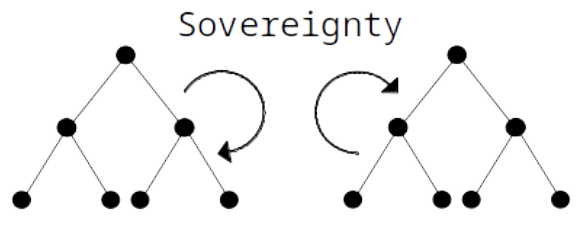

Federated Confederated

Figure 3: Some varieties of centralized and decentralized systems. 


\section{Recentralization}

While much of the literature on decentralization has been predicated on some degree of advocacy for it, the field of practice has raised questions about whether any such process is what it seems. Before long, the term's capaciousness exacts a cost.

\section{Centralizing politics by decentralizing}

By the mid-nineteenth century, Alexis de Tocqueville could see a pattern at work in post-revolutionary France. "When a nation abolishes aristocracy, centralization follows as a matter of course," he wrote. "Every thing tends toward unity of power, and it requires no small contrivance to maintain divisions of authority" (Tocqueville et al., 1998, p. 82). Centralization, he further surmised, "increases in depth at the same time it diminishes in appearance" (Schmidt, 2007, p. 10). This paradox recurs with remarkable consistency.

Consider, for instance, the realm in which Bastiat envisioned une force irrésistible de décentralisation: political economy. Antitrust laws sought to protect competition against the Gilded Age's concentrations of market power, but doing so produced centralized bureaucracies that determined which concentrations were and weren't licit. Those regulations and others were later weakened in many countries in the hopes of decentralizing markets to regulate themselves, which produced new heights of concentrated wealth and political influence (Khan \& Vaheesan, 2017).

Legal scholar Jerry Frug (1993) identifies decentralization as a consistent longing throughout US history, tied to distrust of central government and to an expansive individualism that presages the longing for self-sovereignty among blockchain startups. Drawing on feminist critique, he calls this longing into question. The quest for decentralization, he contends, relies on a the presumption of a "centered subject," an autonomous, isolated, and mostly fictional kind of individual. And it is a fiction with consequences; for instance, Frug shows how such assumptions lend legal preference to more atomized suburban ways of life over the interconnected sociality of cities.

The language of "states' rights" against federal authority has served to embolden concentration of power along racial lines; "right to work" laws have decentralized labor contracting, protecting the singular authority of the 
employer from the coordinated interference of unions. Such recentralizationfor-some, in turn, imposes another kind of decentralization on the subjectivity of others. Kathleen D. Adrian (1998) observes the "decentered subject" as a pattern among African-American women photographers - "artists that fall outside the circle of white patriarchy" (p. 11). Here, decentralization occurs as a consequence of marginalization.

In the context of international development, economist Rémy Prud'homme (1995) catalogs examples of other such cases. Decentralization processes, he finds, can widen inequalities (by prompting the wealthy to cluster in favorable jurisdictions), reduce responsiveness (by allowing local corruption to fester), and hinder efficiency (by forfeiting economies of scale and macroeconomic oversight). More recently, in an in-depth study of decentralization processes in Uganda, Grossman \& Lewis (2014) conclude that "the proliferation of administrative units likely influences intergovernmental balance of power, contributing to processes of recentralization" (p. 196). Approving more local administration can bolster a national government's popularity, their data suggests, while at the same time leaving minority groups more marginalized than before, with less leverage over political and economic forces that affect them. Evidently, centralization once again "increases in depth at the same time it diminishes in appearance."

\section{The Internet's Achilles' heels}

Fears that the decentralized Internet might become somehow centralized date back to its early days. Tim Berners-Lee (1999), among others, expressed concern about the Domain Name System (DNS), which is a semi-decentralized federation overseen centrally by the then quasi-governmental (now nongovernmental) organization ICANN. He referred to DNS as a "centralized Achilles' heel by which it can all be brought down or controlled" (p. 126). Yet years later, this structurally centralized feature of the Internet rarely represents a source of trouble. More obviously worrisome has been the dominance of a few firms like Google and Facebook, whose platforms oversee a significant majority of US Web traffic, and which have come to dominate activities like advertising, news consumption, and political communication as a result. (Centralization is even more intensive in China, where Tencent and Baidu play similar roles while increasingly serving as an arm of the national government.) Internet access and traffic flows have also fallen under the control of remarkably few entities, including telecoms like Comcast and 
Verizon; less visibly to users, a few content-delivery networks like CloudFlare and a few cloud providers like Amazon Web Services wield overwhelming market power. Regardless of any decentralization in the underlying technology, economic imperatives - such as delivering the returns that venture-capital investors expect - have produced centralized networks. For investors, the urge to monopolize market power in the short term promises greater returns than maintaining a network with widely distributed points of control.

In 1999, Berners-Lee did not anticipate this threat; "Happily," he wrote, "the Web is so huge that there's no way any one company can dominate it" (p. 133). Nearly two decades later, his outlook has taken a darker turn. "For people who want to make sure the Web serves humanity, we have to concern ourselves with what people are building on top of it," he told a Vanity Fair reporter (Brooker, 2018). "That feeling of individual control, that empowerment, is something we've lost." Again and again, decentralized technologies do not guarantee decentralized social outcomes.

Berners-Lee originally envisioned Web browsers as both viewers and editors, making authorship as commonplace as surfing. But as the popular commercial browsers offered mainly the viewing functionality, a server-client hierarchy tended to prevail over most people's experience of the early Web, rather than peer-to-peer interactions. Later, even the subversive peer-to-peer file sharing networks adopted server-like "ultra-peers" and "super-nodes" in order to ensure faster indexing and searching (Loban, 2004), and to address a long tail of widespread free-riding (Adar \& Huberman, 2000). The urge for smoother user experience has steered other decentralized protocols into centralization as well; offering a clean interface and hosted storage, popular providers like Yahoo and Google have made email appear less like the open, federated network that it is and more like a handful of closed, centralized platforms. Among software developers, too, Linus Torvalds's Git version-control system is now primarily used not through the distributed storage among users for which it was designed but through GitHub, a proprietary repository and social network, which Microsoft purchased in 2018 for $\$ 7.5$ billion. Socialmedia platforms that once seemed to spell an end to authoritarian regimes, by broadcasting a vast plurality of voices, have ushered in a global authoritarian renaissance (Ferguson, 2018; Tufekci, 2018).

As David Golumbia (2016) suggests, there seems to be a general principle at play: "Computerization is always going to promote centralization even as it promotes decentralization - often in one and the same motion." 


\section{Blockchains to the rescue}

Bitcoin and other blockchain systems may seem to offer an antidote to such phenomena - a fuller, more robust form of decentralization, with cryptographic security and shared databases that require no central authority. This has introduced widespread innovation (but uncertain usefulness) in financing, governance, and network design. Yet early in Bitcoin's transition from concept to adoption, multiple breaches of the popular Mt. Gox exchange between 2011 and 2014 had cascading effects across the system. As with email and Git, even on a decentralized network users were clustering around a convenient platform; more recently, Coinbase has become the centralized portal many users use to reach the decentralized network. A later, notorious blockchain hack was that of the Ethereum "DAO," a collaborative venture fund whose name stands for "decentralized autonomous organization." Due to a bug in the DAO's smart contracts it was compromised, at the cost of millions of dollars in Ethereum's cryptocurrency. Largely thanks to the centralized, charismatic authority of Ethereum founder Vitalik Buterin, the network's users performed a "hard fork" that essentially reversed the hack (DuPont, 2017). He had by then adopted the role of "benevolent dictator for life" common among open-source software communities.

As Buterin (2017) himself points out, the agreed-on database of a blockchainbased network is itself a form of centralization, enshrining as authoritative one body of knowledge and not others. These networks generally run on open-source software and protocols, enabling replication and modification, which some contend is a key expression of their decentralization. But the recurrent exponential distributions due to network effects place limits on what such replication can accomplish. In mid-2018, the market capitalization of Bitcoin ( $\$ 116$ billion), the most valuable crypto-network, was twice that of the second most valuable, Ethereum ( $\$ 49$ billion), which was worth twice as much as the third most valuable ( $\$ 19$ billion), after which the curve begins to flatten into a long tail. ${ }^{5}$ If one doesn't like the rules of the Bitcoin protocol, one is unlikely to replace it with something that will be equally valuable. Such exponential patterns appear, also, in the distribution of wealth among Bitcoin accounts, which is more unequal than the remarkably unequal global economy as a whole, especially thanks to the accumulations of early adopters (BambouClub, 2017). More troubling is the centralization of Bitcoin's proof-of-work mining economy, which has at times posed the danger of a so-called 51 percent attack, in which one army of mining machines has

\footnotetext{
${ }^{5}$ According to listings at coinmarketcap.com.
} 
so much power over the system that it can change the state of the blockchain unilaterally (Eyal \& Sirer, 2013). This kind of centralization could undermine the network.

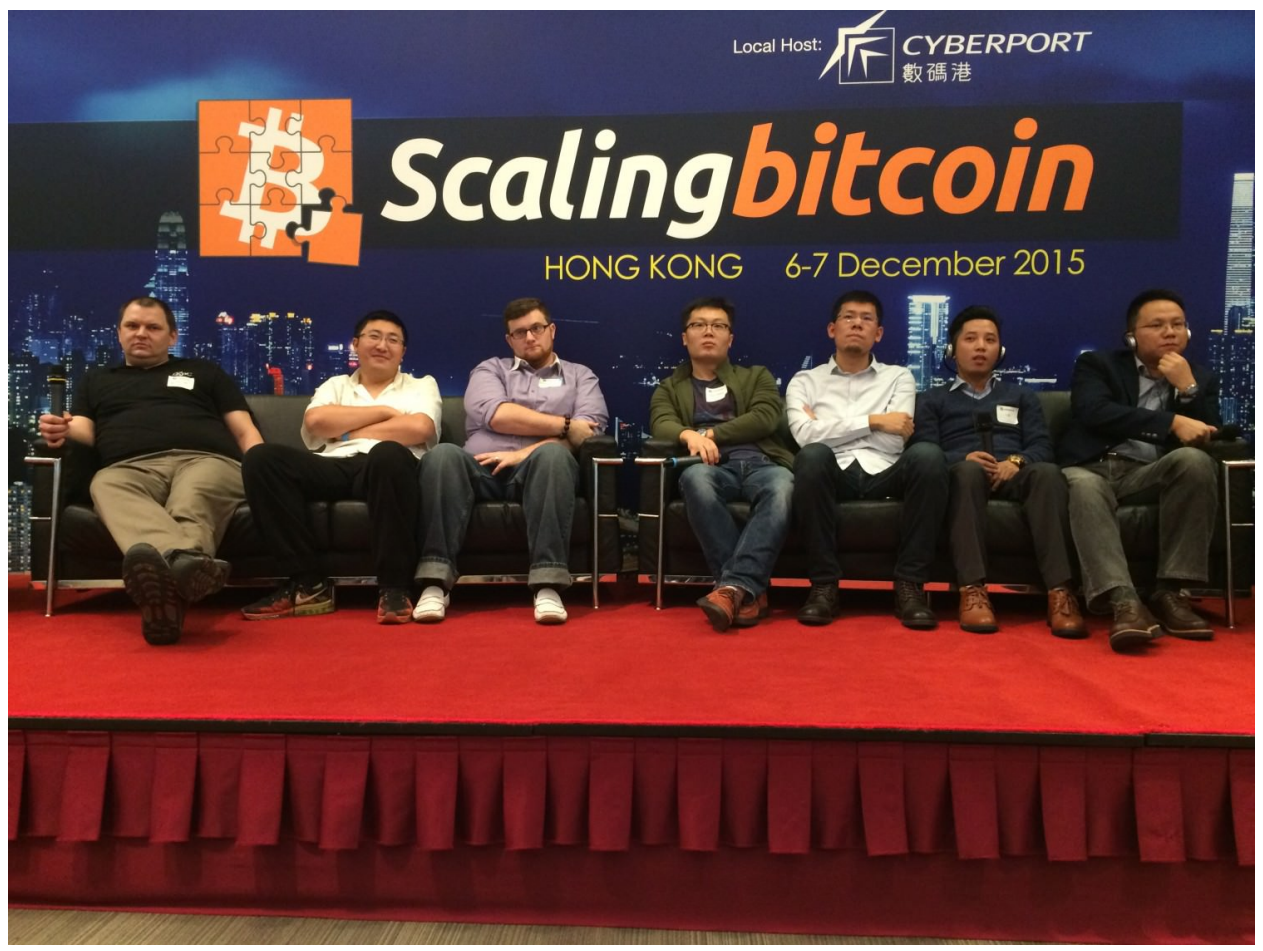

Figure 4: "can we really say that the uncoordinated choice model is realistic when $90 \%$ of the Bitcoin network's mining power is well-coordinated enough to show up together at the same conference?" (Buterin, 2017)

Crypto-networks have typically organized certain activities and personnel through a central, legal organizations such as the Bitcoin Foundation (incorporated in 2012 in the United States) and the Ethereum Foundation (2014, Switzerland). Meanwhile, in order to bypass the costs and complexities of a public blockchain, commercial applications of blockchain technologies have tended to occur through networks with centrally managed control and access - in experiments ranging from supply-chain management for Walmart to blockchain-managed trading for Goldman Sachs. Some of the most prominent public blockchains, such as EOS and IOTA, have employed intentionally centralizing features to improve performance and ease adoption. Arewedecentralizedyet.com is a monument to the blockchain community's 
anxieties of centralization, its Achilles' heels. For a set of the most popular crypto-networks, the website tracks the distribution of mining power, the token supply, and the codebases at work. The consistent pattern is clustering along each of these metrics.

What is it, then, that blockchain technology decentralizes? Certainly the means of access and the modes of authentication are not so obviously unitary as in systems like Facebook or national governments. The databases are on no single company's servers. Yet even in these earliest years of cryptonetwork experiments, it is not clear that authority, trust, or wealth are being meaningfully decentralized - the things that apparently concerned Satoshi Nakamoto at the outset and that are likely to concern future adopters.

The Satoshi Oath further warns, "If it becomes compulsory to take part in a decentralised system, the system itself becomes an oppressive authority in its own right" (Brekke, 2016). Legal scholar Alan Cunningham (2016) contends that the more power blockchain protocols obtain, the less space remains for human agency. Galloway's thesis on the hegemony of protocols, written before Bitcoin existed, repeats itself. Some crypto-enthusiasts have begun to agree, calling for a departure from the language of decentralization altogether (Bair, 2018; Sheng, 2018). But for most, in the culture of BUIDL and HODL, the answer to recentralization is retrenchment.

\section{Missing pieces}

As we have seen, decentralization in one part of a system consistently coincides with centralization in another part. A tragic hue accrues before long to any sub-genre of decentralization-talk. Tragedy binds its subjects, both in shared mourning and resolve. There is always more work to do, so the danger of a failed ambition becomes galvanizing. This has usefulness, like decentralization-talk itself. It can also start to look like cognitive dissonance (Festinger, 1962).

I do not offer a theory here for why recentralization happens because I have come to regard recentralization as an illusion. The center never departed in so many cases where we hear the cry of decentralization - it only shifted and took time for proper reconstitution. The shift was not noticed because people were too busy speaking of decentralization.

Rampant recentralization, then, is less a structural pattern than a rhetorical one. More than a stable concept, decentralization is a frame. A canonical 
synthesis of framing theory puts the matter this way: "To frame is to select some aspects of a perceived reality and make them more salient ...to promote a particular problem definition, causal interpretation, moral evaluation, and/or treatment recommendation" (Entman, 1993, p. 52). Framing is, by this account, a matter of "selection" and, through it, "salience." This is a preInternet-bubble formulation, and framing theory has deservedly fallen into hard times of its own (Cacciatore, Scheufele, \& Iyengar, 2016), but perhaps it is a kind of justice that this old, simple notion of selective emphasis seems to describe the brave, new claims of decentralizers so well. The meaning of decentralization-talk has become, above all, that decentralization matters more than anything else.

As framing theories expect, there are various kinds of equivalent, also-true emphases available. One could tell the story of reducing the power of a central government as creating a power vacuum. One could stress that Internet networks supplant regionally bound publishing infrastructures with immediately global ones. One could tell the story of Bitcoin as replacing a dynamic money-creation mechanism with one that is fixed and predictable. None of these dwells on the story of decentralization, but each of these competing stories is valid and arguably just as significant.

When practitioners and scholars feel pressed to specify what decentralization means, they have had to turn to diverse forms of description, to diverse metaphors. Critics (e.g., Winner, 1986; Tocqueville et al., 1998) have recognized the ruse of decentralization early on but are mostly ignored. Decentralization can be a useful rallying cry, and it bears liberating truths, but it also obscures a fuller reality. A case of alleged decentralization is almost certainly more accurately, modestly described as a matter of broader realignment or reorganization. Taking the incomplete ambition of decentralization as the whole story can mean neglecting the most pernicious features of the realignments underway.

\section{Postredecentralization: Conclusions}

When we notice the degree to which decentralization has become not just a technical principle but a performative aspiration, the need for better theorizing it becomes all the more urgent. When we recognize decentralization-talk as a performative act of framing, and a choice with particular social, cultural, and political consequences, we cannot accept technology as a substitute for taking social, cultural, and political considerations seriously. Decentralized 
technology does not guarantee decentralized outcomes.

Any theory of decentralization must account for the social function of the term's use as a floating signifier, and one with multiple meanings in multiple contexts. This has allowed people with diverse outlooks - for instance, anarchists and corporate executives - to operate within the same discourse and develop technologies in more or less coordinated fashion. But, as in political science, a theory of decentralization should specify a typology of meanings that the term encompasses, enabling more specific uses of the term with less danger of sowing confusion. Such typologies, sensitive to particular forms and layers through which decentralization can occur, are beginning to appear in emerging crypto-network discourses, among both scholars (Rauchs et al, 2018) and practitioners (Sheng, 2018).

Such specificity should also be brought to bear with respect to patterns of centralization, or recentralization, recognizing that such formations are likely outcomes of a reorganization process that looks like decentralization. Galloway's account of the protocol as a mechanism of central control is an example of this, but experience suggests there are other mechanisms of centralization as well- such as the accumulation of network effects, corporate financing, regulatory policies, and more. A theory of decentralization must include a theory of centralization as well.

Critical use of the decentralization frame should also avoid demonizing anything with a center. Centralized structures can have virtues, such as enabling publics to focus their limited attention for oversight, or forming a power bloc capable of challenging less-accountable blocs that might emerge. Centralized structures that have earned widespread respect in recent centuries - including governments, corporations, and nonprofit organizations - have done so in no small part because of the intentional design that went into those structures. Surely such intentional design is preferable, both philosophically and in practical outcomes, than whatever centralized formations appear by surprise when most people are talking about decentralization. A centralized, quasidemocratic institution as flawed as the US Federal Reserve System, which Satoshi Nakomoto sought to replace, has features arguably more accountable to the common good than the ad-hocracy of Bitcoin miners. Centralized antitrust authorities have long helped foster more decentralized markets. Even those committed to the ambition of decentralization should recognize that accountable centralization may be necessary, and even essential, for protecting what they hold dear.

Decentralizers would do well to consider past lessons of such accountable cen- 
tralization. For instance, rather than viewing technologies such as blockchains as a rude departure from all preceding political theory, they should enter into a conversation with legacies such as the separation of powers, theories of sovereignty, and antitrust law to glean strategies for employing appropriate centralization to protect decentralized activities (e.g., Reijers et al., 2018). The difference in kind between the politics of the past and of the imagined future may be smaller than some assume.

Non-state examples will surely be instructive as well. The lessons of cooperative business (Schneider, 2018) demonstrate means of democratic governance around shared economic goals, as well as structures that create economies of scale to support smaller, diverse enterprises rather than replacing them with conglomerates. (Some blockchain projects - such as FairCoin, RChain, and Aragon - have attempted to employ cooperatives in their community structures already.) More broadly, governance practices surrounding what Elinor Ostrom called "common-pool resources," or more colloquially "the commons," can be instructive for determining how to manage the centralized components of otherwise decentralized networks (Rozas, Tenorio-Fornés, Díaz-Molina, \& Hassan, 2018). Such practices are already at work to some degree in protocol-design bodies like the World Wide Web Consortium and might be implemented much more widely and intentionally.

As the prefix de suggests, ideologies of decentralization tend to emphasize what they negate - a freedom from rather than a freedom to. In the formulation of Hirschman (1970), they focus on the opportunity for exit rather than the capacity of voice. Crypto-networks in particular are frequently advertised in terms of what and whom they circumvent. But just as important is the question of how new systems of interaction incline us to coalesce, and what kinds of levers they lend us to shape them from within. As blocs of power form in these systems, who controls them and how? What protections are necessary to ensure that the forms of decentralization that matter most to us can persist? If an important system goes awry, as any inevitably will, what recourse do participants have to course-correct? Any ambition for decentralization will remain chronically incomplete without accompanying ambitions for accountability. 


\section{References}

Adar, E., \& Huberman, B. A. (2000). Free riding on Gnutella. First Monday, $5(10)$.

Adrian, K. D. (1998). The Decentralization of Subject in African American Feminist Photography: Constructing Identity based on Representation and Race in the Work of Lorna Simpson, Carrie Mae Weems and Clarissa Sligh. disClosure: A Journal of Social Theory, 7(1), 3.

Aragon. (2018, March). The Fight for Freedom. https://www.youtube.com/watch?v=AqjIWmiAidw.

Arquilla, J., \& Ronfeldt, D. F. (2000). Swarming and the Future of Conflict. Santa Monica, CA: RAND.

Backus, J. (2018, July). Resistant protocols: How decentralization evolves.

Bair, T. (2018, February). The True Enemy of Decentralization.

BambouClub. (2017, September). Are You in the Bitcoin 1\%? A New Model of the Distribution of Bitcoin Wealth. Medium.

Baran, P. (1964). On Distributed Communications. Santa Monica, CA: RAND Corporation.

Baran, P. (2002). The Beginnings of Packet Switching: Some Underlying Concepts. IEEE Communications Magazine, 40(7), 42-48. https://doi.org/ 10.1109/MCOM.2002.1018006

Bastiat, F. (1849). Popular Fallacies Regarding General Interests. (G. R. Porter, Trans.). London: Simms and M'Intyre.

Benkler, Y. (2006). The Wealth of Networks: How Social Production Transforms Markets and Freedom. New Haven [Conn.]: Yale University Press.

Benkler, Y. (2016). Degrees of Freedom, Dimensions of Power. Daedalus, 145(1), 18-32. https://doi.org/10.1162/DAED_a_00362

Berners-Lee, T. (1999). Weaving the Web: The Original Design and Ultimate Destiny of the World Wide Web by Its Inventor. San Francisco: HarperSanFrancisco.

Bonnal, J. (n.d.). A History of Decentralization. The Online Sourcebook on Decentralization and Local Development. http://www.ciesin.org/decentralization/English/General/histor 
Bosquet, A. (2011). The Scientific Way of Warfare: Order and Chaos on the Battlefields of Modernity. Columbia University Press.

Brekke, J. K. (2016, September). Dissensus protocol? Distributing Chains.

Brooker, K. (2018, July). "I Was Devastated": The Man Who Created the World Wide Web Has Some Regrets. Vanity Fair. https://www.vanityfair.com/news/2018/07/the-man-who-created-theworld-wide-web-has-some-regrets.

Burke, J. (2018, July). Pathway to Decentralisation. Outlier Ventures.

Buterin, V. (2013). A Next-Generation Smart Contract and Decentralized Application Platform. Ethereum. https://github.com/ethereum/wiki/blob/oldbefore-deleting-all-files-go-to-wiki-wiki-instead/old-whitepaper-forhistorical-reference.md.

Buterin, V. (2017, February). The Meaning of Decentralization. Medium.

Cacciatore, M. A., Scheufele, D. A., \& Iyengar, S. (2016). The End of Framing as we Know it ... and the Future of Media Effects. Mass Communication and Society, 19(1), 7-23. https://doi.org/10.1080/15205436.2015.1068811

Civil Media Company. (2018). The Civil White Paper. Civil. http://civil.co/white-paper/.

Coolidge, M. (2018, June). CVL Tokens: A Primer. Civil blog.

Cunningham, A. (2016). Decentralisation, Distrust \& Fear of the Body of Crypto-Law. SCRIPTed, 13(3), 235-257. https://doi.org/10.2966/scrip. 130316.235

De Filippi, P., \& Wright, A. (2018). Blockchain and the Law: The Rule of Code. Harvard University Press.

Deleuze, G., \& Guattari, F. (1987). A Thousand Plateaus: Capitalism and Schizophrenia. (B. Massumi, Trans.). University of Minnesota Press.

Dietz, J., \& Bontje, J. (2014, March). I Want Half! Marriage Smart Contract for Ethereum. https://www.youtube.com/watch?v=zRpziAtk61g.

DuPont, Q. (2017, November). Experiments in Algorithmic Governance : A History and Ethnography of "The DAO," a Failed Decentralized Autonomous Organization. Bitcoin and Beyond (Open Access). https://www.taylorfrancis.com/. https://doi.org/10.4324/9781315211909-8 
Entman, R. M. (1993). Framing: Toward Clarification of a Fractured Paradigm. Journal of Communication, 43(4), 51-58. https://doi.org/10. 1111/j.1460-2466.1993.tb01304.x

Eyal, I., \& Sirer, E. G. (2013). Majority Is Not Enough: Bitcoin Mining Is Vulnerable. arXiv:1311.0243 [Cs]. Retrieved from http://arxiv.org/abs/ 1311.0243

Fanon, F. (2007). The Wretched of the Earth. Grove/Atlantic.

Ferguson, N. (2018). The Square and the Tower: Networks and Power, from the Freemasons to Facebook. Penguin.

Fesler, J. W. (2008). Centralization and Decentralization. International Encyclopedia of the Social Sciences.

Festinger, L. (1962). A Theory of Cognitive Dissonance. Stanford University Press.

Finke, R., \& Stark, R. (2005). The Churching of America, 1776-2005: Winners and Losers in Our Religious Economy. Rutgers University Press.

Fontana, D. (2018). Federal Decentralization. Virginia Law Review, 104(4), 727.

Frug, J. (1993). Decentering Decentralization. The University of Chicago Law Review, 60(2), 253-338. https://doi.org/10.2307/1600075

Galloway, A. R. (2006). Protocol: How Control Exists After Decentralization. Cambridge, Mass.: MIT Press.

Gellman, R. (1996). Disintermediation and the Internet. Government Information Quarterly, 13(1), 1-8. https://doi.org/10.1016/S0740-624X(96) 90002-7

Goldhaber, M. H. (1997). The Attention Economy and the Net. First Monday, 2(4). https://doi.org/10.5210/fm.v2i4.519

Golumbia, D. (2016). Computerization Always Promotes Centralization Even As It Promotes Decentralization. In Digital Humanities and Digital Media: Conversations on Politics, Culture, Aesthetics and Literacy. Open Humanites Press.

Goodwyn, L. (1978). The Populist Moment: A Short History of the Agrarian Revolt in America. Oxford University Press. 
Green, M. (2017, July). But it seems like they are trapped in some horrible Sartre play where everyone has to use the word "decentralized" to mean different things. @matthew_d_green. Tweet.

Greenberg, A. (2017). How Anarchist Bitcoin Coder Amir Taaki Wound Up Fighting ISIS in Syria. Wired.

Grossman, G., \& Lewis, J. I. (2014). Administrative Unit Proliferation. American Political Science Review, 108(01), 196-217. https://doi.org/10. $1017 /$ S0003055413000567

Hafner, K., \& Lyon, M. (1996). Where Wizards Stay Up Late: The Origins of the Internet. New York: Simon \& Schuster.

Hardt, M., \& Negri, A. (2005). Multitude: War and Democracy in the Age of Empire. Penguin.

Hinman, W. (2018, June). Digital Asset Transactions: When Howey Met Gary (Plastic). San Francisco.

Hirschman, A. O. (1970). Exit, Voice, and Loyalty: Responses to Decline in Firms, Organizations, and States. Harvard University Press.

Hock, D. (2005). One From Many: VISA and the Rise of the Chaordic Organization. San Francisco: Berrett-Koehler Publishers.

In the Mesh. (2018, April). Manifesto. In the Mesh.

Johnston, D. A. (2014, August). Everything Will Be Decentralized. Medium.

Jones, C., \& Spicer, A. (2005). The Sublime Object of Entrepreneurship. Organization, 12(2), 223-246. https://doi.org/10.1177/1350508405051189

Kahle, B. (2015, August). Locking the Web Open: A Call for a Decentralized Web. http://brewster.kahle.org/2015/08/11/locking-the-web-open-a-call-fora-distributed-web-2/.

Katz, E. (1988). Disintermediation: Cutting Out the Middle Man. Intermedia, 16(2), 30-31.

Khan, L. M., \& Vaheesan, S. (2017). Market Power and Inequality: The Antitrust Counterrevolution and Its Discontents. Harvard Law $\&$ Policy Review, 11, 235-294.

Kleiner, D. (2016). Counterantidisintermediation. In T. Scholz \& N. Schneider (Eds.), Ours to Hack and to Own: The Rise of Platform Cooperativism, 
a New Vision for the Future of Work and a Fairer Internet. New York: OR Books.

Leo XIII. (1891, May). Rerum Novarum: On Capital and Labor.

Lewis, S. J. (2018, August). In it's simplest definition... @SarahJamieLewis. Twitter.

Litvack, J., \& Seddon, J. (Eds.). (2002). Decentralization Briefing Notes. World Bank Institute. https://doi.org/10.1596/978-1-4648-0484-7

Loban, B. (2004). Between Rhizomes and Trees: P2P Information Systems. First Monday, 9(10).

Mathews, R. (2009). Jobs of Our Own: Building a Stakeholder Society: Alternatives to the Market and the State (2nd ed.). Irving, TX: Distributist Review Press.

Maurer, B., Nelms, T. C., \& Swartz, L. (2013). "When Perhaps the Real Problem Is Money Itself!": The Practical Materiality of Bitcoin. Social Semiotics, 23(2), 261-277. https://doi.org/10.1080/10350330.2013.777594

Mehlman, J. (1972). The "Floating Signifier": From Lévi-Strauss to Lacan. Yale French Studies, (48), 10-37. https://doi.org/10.2307/2929621

Meyer, R. (2018). Lina Khan and the "Hipster Antitrust" Movement. The Atlantic.

Miller, A. B. (2015, April). Interviewed: Joel Dietz on Distributed Collaborative Organizations. Shareable. https://www.shareable.net/blog/interviewedjoel-dietz-on-distributed-collaborative-organizations.

Naisbitt, J. (1984). Megatrends: Ten New Directions Transforming Our Lives. Warner Books.

Nakamoto, S. (2009a, February). Bitcoin Open Source Implementation of P2P Currency. P2P Foundation on Ning.

Nakamoto, S. (2009b, January). Bitcoin v0.1 Released. cryptography@metzdowd.com.

Olowu, D. (2001). Decentralization Policies and Practices under Structural Adjustment and Democratization in Africa (No. 4) (p. 37). United Nations Research Institute for Social Development.

Pandey, G. (2015). Off-Centered States: An Appreciation. In C. Krupa \& D. Nugent (Eds.), State Theory and Andean Politics: New Approaches to 
the Study of Rule (pp. 257-266). Philadelphia: University of Pennsylvania Press.

Pius XI. (1931, May). Quadragesimo Anno: On Reconstruction of the Social Order.

Posner, E. A., \& Weyl, E. G. (2018). Radical Markets: Uprooting Capitalism and Democracy for a Just Society. Princeton: Princeton University Press.

Prud'homme, R. (1995). The Dangers of Decentralization. The World Bank Research Observer, 10(2), 201-220. https://doi.org/10.1093/wbro/10.2.201

Rauchs et al, M. (2018). Distributed Ledger Technology Systems: A Conceptual Framework. Cambridge, UK: Cambridge Centre for Alternative Finance.

Reijers, W., Wuisman, I., Mannan, M., De Filippi, P., Wray, C., Rae-Looi, V., ... Orgad, L. (2018). Now the Code Runs Itself: On-Chain and Off-Chain Governance of Blockchain Technologies. Topoi. https://doi.org/10.1007/ s11245-018-9626-5

Robertson, B. J. (2015). Holacracy: The New Management System for a Rapidly Changing World. Henry Holt and Company.

Rozas, D., Tenorio-Fornés, A., Díaz-Molina, S., \& Hassan, S. (2018). When Ostrom Meets Blockchain: Exploring the Potentials of Blockchain for Commons Governance (SSRN Scholarly Paper No. ID 3272329). Rochester, NY: Social Science Research Network.

Schechner, R. (2017). Performance Studies : An Introduction. Routledge. https://doi.org/10.4324/9780203125168

Schmidt, V. A. (2007). Democratizing France: The Political and Administrative History of Decentralization. Cambridge University Press.

Schneider, A. (2003). Decentralization: Conceptualization and Measurement. Studies in Comparative International Development, 38(3), 32-56. https: //doi.org/10.1007/BF02686198

Schneider, N. (2018). Everything for Everyone: The Radical Tradition That Is Shaping the Next Economy. New York: Nation Books.

Sheldrake, P. (2015, August). Decentralization Cannot Be Marketed. The hi:project. https://hi-project.org/2015/10/decentralization-cannot-bemarketed/. 
Sheng, T. (2018, September). Let's Ditch "Decentralized".

Sheppard, S. (2016). Syria's Kurds Experiment With Democracy Amid Civil War. The Atlantic.

Taleb, N. N. (2016). Antifragile: Things That Gain from Disorder. New York: Random House.

Tobin, A., \& Reed, D. (2017). The Inevitable Rise of Self-Sovereign Identity. The Sovrin Foundation.

Tocqueville, A. de. (2004). Democracy in America. Library of America.

Tocqueville, A. de, Furet, F., \& Mélonio, F. (1998). The Old Regime and the Revolution. Chicago : University of Chicago Press.

Torrisi, G., Pike, A., Tomaney, J., \& Tselios, V. (2011). Defining and measuring decentralisation: A critical review.

Treisman, D. (2002, March). Defining and Measuring Decentralization: A Global Perspective.

Tufekci, Z. (2018). How Social Media Took Us from Tahrir Square to Donald Trump. MIT Technology Review.

UNDP, \& Government of Germany. (1999). Decentralization: A Sampling of Definitions (Evaluation of the UNDP Role in Decentralization and Local Governance). United Nations Development Programme.

Winner, L. (1986). The Whale and the Reactor: A Search for Limits in an Age of High Technology. Chicago, UNITED STATES: University of Chicago Press.

World Bank. (n.d.). Different Forms of Decentralization. The Online Sourcebook on Decentralization and Local Development. http://www.ciesin.org/decentralization/English/Genera

Yeung, C.-m. A., Liccardi, I., Lu, K., Seneviratne, O., \& Berners-Lee, T. (2009). Decentralization: The Future of Online Social Networking. In W3C Workshop on the Future of Social Networking. Barcelona: World Wide Web Consortium.

Yuliani, E. L. (2004). Decentralization, deconcentration and devolution: What do they mean? In Interlaken Workshop on Decentralization. Interlaken, Switzerland.

Zhang, G. Z. (2018). Systems Seduction: The Aesthetics of Decentralisation. Journal of Design and Science. https://doi.org/10.21428/2bfc3a68 